\title{
ULTRA SHORT PULSE LASER GENERATED SURFACE TEXTURES FOR ANTI-ICE APPLICATIONS IN AVIATION C205
}

\author{
Gert-willem Römer ${ }^{1}$, Daniel Arnaldo del Cerro ${ }^{1}$, R.C.J. Sipkema ${ }^{2}$, \\ M.N.W. Groenendijk', A.J. Huis in 't Veld ${ }^{1,3}$ \\ ${ }^{1}$ University of Twente, Faculty of Engineering Technology, Chair of Applied Laser Technology, \\ P.O. Box 217, 7500 AE, Enschede, the Netherlands \\ ${ }^{2}$ Lightmotif BV, Drienerlolaan 5, 7522 NB, Enschede, The Netherlands \\ ${ }^{3}$ TNO Science \& Industry, Department Materials Technology, \\ De Rondom 1, 5600 HE, Eindhoven, The Netherlands
}

\begin{abstract}
By laser ablation with ultra short laser pulses in the pico- and femto-second range, well controlled dual scaled micro- and nano-scaled surface textures can be obtained. The micro-scale of the texture is mainly determined by the dimensions of the laser spot, whereas the superimposed nano-structure is the result of socalled laser induced "self organizing nanostructuring". By controlling this micro-nano surface texture, it is possible to modify the natural hydrophobicity of materials.
\end{abstract}

This paper investigates the anti-ice properties of these hydrophobic micro-nano surface textures. Leading edges, engine inlets etc. of airplanes are prone to iceaccretion in certain icing conditions. Ice can distort the flow of air over the wing, reducing the aircrafts aerodynamic performance. Moreover, take-off is not permitted if ice contamination on the aircraft's surfaces exists.

Two materials, popular in aviation, a titanium alloy (Ti-6Al-4V) and a stainless steel (1.4544.9), were laser-machined using UV laser pulses of 6.7 ps at 200 $\mathrm{kHz}$. Surface textures were physically analyzed using optical microscopy and SEM. Coatings, on top of the textures, were applied to create super-hydrophobicity. The hydrophobicity of the surfaces was quantified by contact angle measurements. The anti-ice properties of the surfaces were tested in a climate chamber.

\section{Introduction}

Aircraft operating requirements lay down that unless an aircraft is certified relating to ice protection, it may not take off and/or be operated in icing conditions. That is, unless it is equipped with means for prevention or removal of ice on windshields, wings, empennage, propellers and other parts where ice for- mation will adversely affect the safety of the aircraft [1]. The goal of this research is to mimic the self cleaning effect of a Lotus leaf by laser micromachining, assuming that this Lotus effect contributes to the prevention of ice-accretion [2].

When a hydrophobic material is provided with an optimized fine surface structure, self cleaning surfaces can be achieved, like that of the Lotus leaf, see Figure 1 . That is, the water repelling ability of the Lotus leaf is a result of a dual scaled micro- and nano-structured surface morphology covered with hydrophobic waxes [3]. A droplet on the leaf rests on the protrusions of the surface structures and air is trapped between the droplet and the surface, as described by the Cassie-Baxter equation [4].

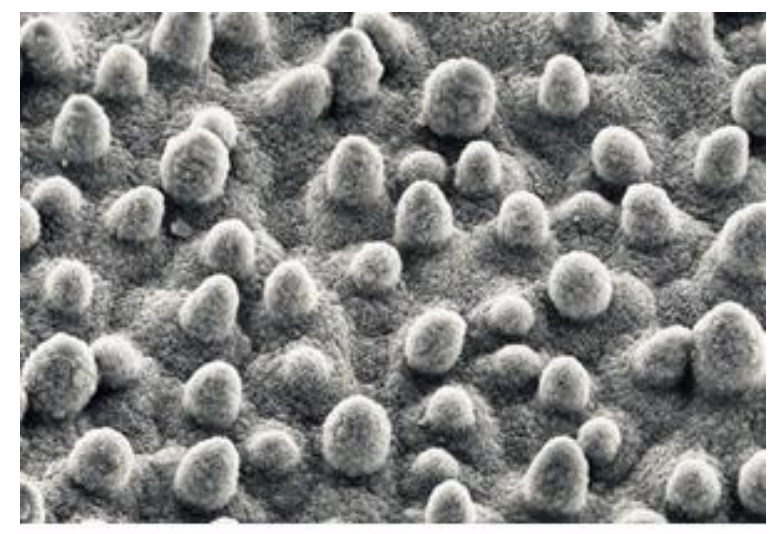

Figure 1 The water repelling ability of the Lotus leaf is a result of a dual scaled micro- and nano-structured surface morphology covered with hydrophobic waxes (Image courtesy of W. Barthlott).

Ultra short laser pulses can accurately ablate a wide range of materials without or very limited thermal damage [5]. Reproducible pulse to pulse ablation, together with the typical ablation depth of about 20 $\mathrm{nm}$ per pulse leads to well defined ablation results. Typical material removal depths are in the range of 
about $10 \mathrm{~nm}$ to about $100 \mathrm{~nm}$ per laser pulse, depending on the material and laser parameters. Feature sizes in the micrometer range, mainly determined by the size of the laser spot, can be achieved while machining. Hence, laser ablation can be used to design a surface morphology which mimics the micrometer scale surface morphology of the Lotus leaf [10].

In laser ablated surfaces, "self organizing nano-structuring”, or Laser Induced Periodic Surface Structures (LIPSS), are frequently observed [6]. Ripple formation due to laser irradiation comprises the growth of wavy surfaces, with periodicity in the $100 \mathrm{~nm}$ range and amplitudes in the $10 \mathrm{~nm}$ range [7]. The periodicity and amplitude of ripples depend in most cases on the fluence, the wavelength, the polarization, and other characteristics of the laser beam. Hence, when combined with a laser ablation texture in the micrometer scale, the LIPPS can mimic the superimposed nano-meter scale of the surface morphology of a Lotus effect.

The goal of this research was to structure the surface of metals by picosecond laser ablation. These textured metals were coated by a thin hydrophobic coating to create a super-hydrophobic surface. Next, the ice-phobic properties of the morphology of the coated surfaces were addressed.

\section{Icing conditions}

Icing occurs when the aircraft is exposed to icing conditions while:

- on the ground, e.g. when stalled on an airstrip,

- in-flight.

When on the ground, ice is formed during icing precipitations like snow, sleet, hoar frost and hail. Hoar frost forms from atmospheric water vapour. It can form in apparently clear air and can occur at air temperatures above freezing point if the aircraft skin temperature is below freezing point. Freezing fog may cover an aircraft when it is on the ground. The provision of ground de-icing facilities has provided considerable operational benefits to the aviation business. Currently fluids containing freezing point suppressants provide the means of both clearing and protecting aircraft on the ground.

Because of the danger of flight in icing conditions, the civil certification authorities in the USA (Federal Aviation Administration, FAA), as well as in Europe (European Aviation Safety Agency, EASA) have established rules for so-called "ice-certification".
These are laid down for transport aircraft in CS/FAR 25.1419 [1]. Smaller general aviation aircraft have to follow the rules of CS/FAR Part 23 that are similar to Part 25 with respect to ice certification. The basic demand of all these regulations is that safe flight must be maintained in all permitted icing conditions.

Supercooled droplets will tend to freeze when they encounter ice particles or solid structures such as aircraft. This process is responsible for the rapid growth of ice formations which may cause aerodynamic and control problems in flight. The type of ice accretion being formed depends on size and shape of the aircraft part and on several factors like: temperature, speed, liquid water content (LWC), droplet size and exposure time.

Appendix C of CS/FAR 25 presents meteorological data on icing conditions [1]. The maximum continuous intensity of atmospheric icing conditions (known as "Continuous Maximum icing") is defined by the variables of the cloud liquid water content (LWC), the mean effective diameter of the cloud droplets and the ambient air temperature. A mean effective droplet diameter (MED) of 50 microns is applied to define the maximum impingement limits, which defines the extent of the ice protection. For the ice protection system performance analysis and testing usually a MED of 20 microns is usually considered. On most aircraft 45 minutes holding in CS/FAR 25 Appendix C, Continuous Maximum icing conditions is selected as the design condition for ice protection systems. During holding usually a speed about $10 \%$ above the minimum drag speed is chosen. This means that during holding the aircraft lift coefficient remains constant and consequently, the holding speed is not constant but becomes a function of aircraft weight. Typical holding conditions are in the 160-220 kCAS speed range (about 96 and 103 $\mathrm{m} / \mathrm{s}$ ) between 10000 and $15000 \mathrm{ft}$ altitude respectively.

Summarizing, the design of an anti-icing system should be based on (in-flight) icing conditions at aircraft level, holding in Continuous Maximum icing:

- Mean effective droplet diameter: $20 \mu \mathrm{m}$,

- Liquid water content: $0.5 \mathrm{~g} / \mathrm{m}^{3}$,

- Temperature $-5{ }^{\circ} \mathrm{C}$ (of droplets and aircraft parts),

- Holding time: 45 minutes,

- Wind speed: $100 \mathrm{~m} / \mathrm{s}$.

In these conditions, the maximum water catch occurs. These conditions were used to design the desired surface morphology of the aircraft surfaces prone to ice accretion. 


\section{Experimental setup}

A Trumpf TruMicro laser source, with a central wavelength of $1030 \mathrm{~nm}$ was used for generation of the laser pulses. But for the experiments, a Second and a Third Harmonic Generation (SHG \& THG) units were applied to generate wavelengths in the visible $(515 \mathrm{~nm})$ and $\mathrm{UV}$ range $(343 \mathrm{~nm})$, with a maximum available average power of about $25 \mathrm{~W}$ and $15 \mathrm{~W}$ at $400 \mathrm{kHz}$, respectively. The pulse duration was constant at $6.7 \mathrm{ps}$ for all experiments.

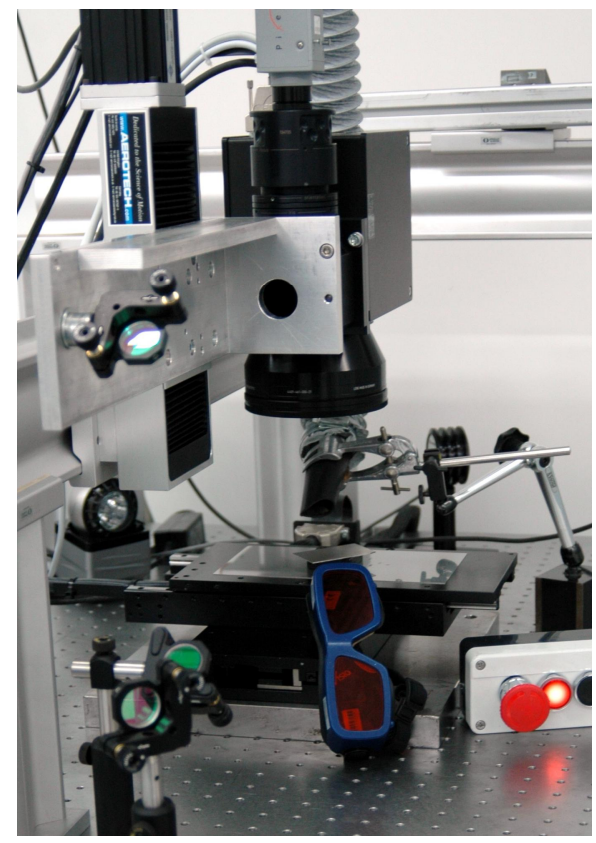

Figure 2 Laser setup.
The laser radiation was linearly polarized (horizontally). Manipulation of the beam over the samples was accomplished by a two mirror galvo scanner system, see Figure 2. A $103 \mathrm{~mm} \mathrm{f} \theta$-lens focused the beam to a spot with a diameter of about $30 \mu \mathrm{m}$. However, due to the Gaussian power density profile of the laser beam and the ablation threshold, the effective beam diameter is about $22 \mu \mathrm{m}$. This beam diameter allows surface textures to be ablated with a feature size of the same order of magnitude as the expected under cooled water droplets $(20 \mu \mathrm{m})$. The focused laser beam was scanned over the sample in a hatched pattern, with a predefined hatch distance. The hatch pattern was rescanned a number of times (referred to as "overscans") to achieve the desired depth of the texture (also about $20 \mu \mathrm{m}$ ). The fluence was measured at the exit of the scanner system and averaged across the irradiated area, as the energy distribution of the laser beam is Gaussian. In all experiments the angle of incidence of laser radiation was perpendicular to the specimen surface. The samples were irradiated in air, in a clean room, at room temperature.

Two materials, widely applied in aviation, were investigated in this study: a titanium alloy (Ti-6Al-4V) and a stainless steel (Werkstoff-Nr. 1.4544.9). All specimens were plates of $1 \mathrm{~mm}$ thickness. The titanium samples were polished to optical flatness, roughness $R_{\mathrm{a}}<50 \mathrm{~nm}$.

Two types of coatings, to be applied to the steel samples (only) were selected for their hydrophobic properties: a mono layer of Perfluorinated OctylTrichloroSilane (FOTS) and a $8 \mu \mathrm{m}$ layer of HexaMethylDiSilOxane (HMDSO).

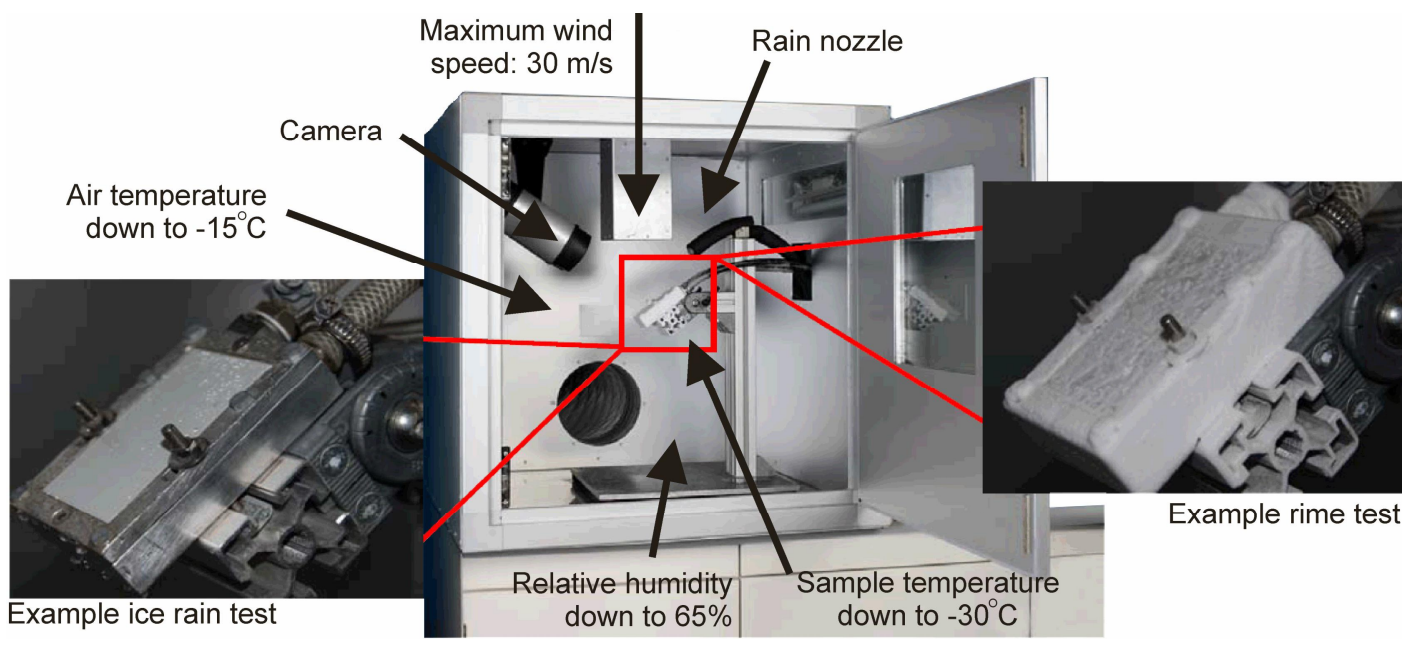

Figure 3 Eisomat, a climate chamber used to assess the behaviour of the samples under icing conditions, of the Fraunhofer Institut für Fertigungstechnik und Angewandte Materialforschung (IFAM) in Bremen (Germany). 
FOTS coatings are known to increase the hydrophobicity of substrates. These compounds decrease the surface energy due to the presence of non polar chains of methyl groups, that are attached to the substrate trough a chemical bond. Chlorosilanes are hydrolyzed on a first step, forming hydroxide groups, thus increasing the molecule affinity for the surface. Then the adsorption of the molecules on the surface occurs while they link each other trough $\mathrm{Si}-\mathrm{O}-\mathrm{Si}$ bonds, to form the coating [8]. Ideally, a monolayer is formed over the surface, without compromising the surface morphology of the specimen. The combination of chemical hydrophobicity with the surface double scale roughness produces the superhydrophobic effect. The process of applying the FOTScoating consisted of a cleaning and oxidizing step, using a reactive oxygen plasma (Plasmafab 508, Electrotech; $10 \mathrm{~min}, 500 \mathrm{~W}, \mathrm{pO} 2=16 \mathrm{mbar}$ ) to remove adsorbed impurities [8]. Next, the sample was extensively rinsed first with iso-propanol, then with ultra pure water and dried with nitrogen. Next, the sample was stored together with a few microliters of FOTS in a dry sealed glass box. A heat treatment was carried out at $120^{\circ} \mathrm{C}$ for 5.5 hours in a nitrogen flushed oven. Afterwards the coated sample was allowed to cool down in a desiccator [8].

HMDSO coated stainless steel sample was kindly provided by the Fraunhofer Institut für Fertigungstechnik und Angewandte Materialforschung (Fraunhofer IFAM) in Bremen (Germany). It was prepared by plasma enhanced chemical vapour deposition (PECVD). This coating has similar properties as FOTS, as it increases the hydrophobicity of the substrate. This is due to the low surface energy originated by the methyl groups that are attached to the surface trough a dense Si-O-Si net. To test the laser-machinability of such a coating, a layer HMDSO was applied to the sample, whereas the FOTS layer is a monolayer. The thickness of the HMDSO layer as provided was $8 \mu \mathrm{m}$.

The hydrophobic properties of the samples, at room temperature, were determined by a video based optical contact angle measuring device, the OCA 15 plus of DataPhysics Instruments using distilled deionized water droplets of 10 microliter.

The morphology of the surface structures was analysed with scanning electron microscopy (SEM).

The behaviour of the samples under icing conditions was assessed in a climate chamber, referred to as the Eisomat, developed by the Fraunhofer IFAM institute, see Figure 3. During the rime tests first a dummy sample was placed in the sample holder of the
Eisomat for 45 minutes, allowing the holder and the chamber to cool down to a temperature of $-15^{\circ} \mathrm{C}$ at a relative humidity of $88 \%$ and air temperature of $1^{\circ} \mathrm{C}$. Next, the dummy sample was replaced by one of the specimen under consideration. After 20 minutes, during which rime is formed. The thickness of the rime layer was measured by a measurement comb.

During the ice rain test the samples were placed in the sample holder, allowing the samples for $45 \mathrm{~min}$ utes to cool down to $-5^{\circ} \mathrm{C}$ at a relative humidity of $65 \%$ and a wind speed of $9 \mathrm{~m} / \mathrm{s}$ at $-5^{\circ} \mathrm{C}$. Then, water of $0^{\circ} \mathrm{C}$ was sprayed for 10 seconds and a photograph was taken of the sample's surface. Next, after 10 minutes a second photograph was taken. Subsequently, water was sprayed again for 10 seconds. Then, after 5 minutes a third photograph was taken. Finally, the wind speed was increased to $30 \mathrm{~m} / \mathrm{s}$ for a few seconds, after which a fourth photograph was taken. Unfortunately, the test samples could not be tested in the Eisomat according to the "Continuous Maximum icing", as the Eisomat can not achieve these conditions. However, a qualitative comparison of the icephobic behaviour can be made between untextured and laser-textured surfaces.

\section{Experimental results}

\section{Surface morphology}

Figure 4 and Figure 5 show SEM images of the uncoated textured and untextured titanium sample and the uncoated stainless steel sample respectively. The surface morphology consists of laser ablated tracks or "valleys" of a depth of about $20 \mu \mathrm{m}$, and tapered peaks. On these tapered protrusions a water droplet will rest, trapping air in the valleys. The tapered shape of the peak is the result of the Gaussian energy density distribution of the focussed laser beam and the lower ablation rate in the valleys. On top of the peaks redeposited material can be observed. Careful analysis of SEM images show straight valleys in one direction of the hatch, and wavy or saw tooth-like valleys, in the perpendicular direction. This is attributed to a slightly elliptical shape of the laser spot. The SEM images at larger magnification unveil the nano scaled LIPSS on top of the micro scale morphology. Comparing Figures 4 and 5 shows that similar structures are obtained in different type of metals with basically the same processing parameters. In addition, it was found that similar surface morphology could be achieved, when processing at the two laser wavelengths of $515 \mathrm{~nm}$ and $343 \mathrm{~nm}$. 

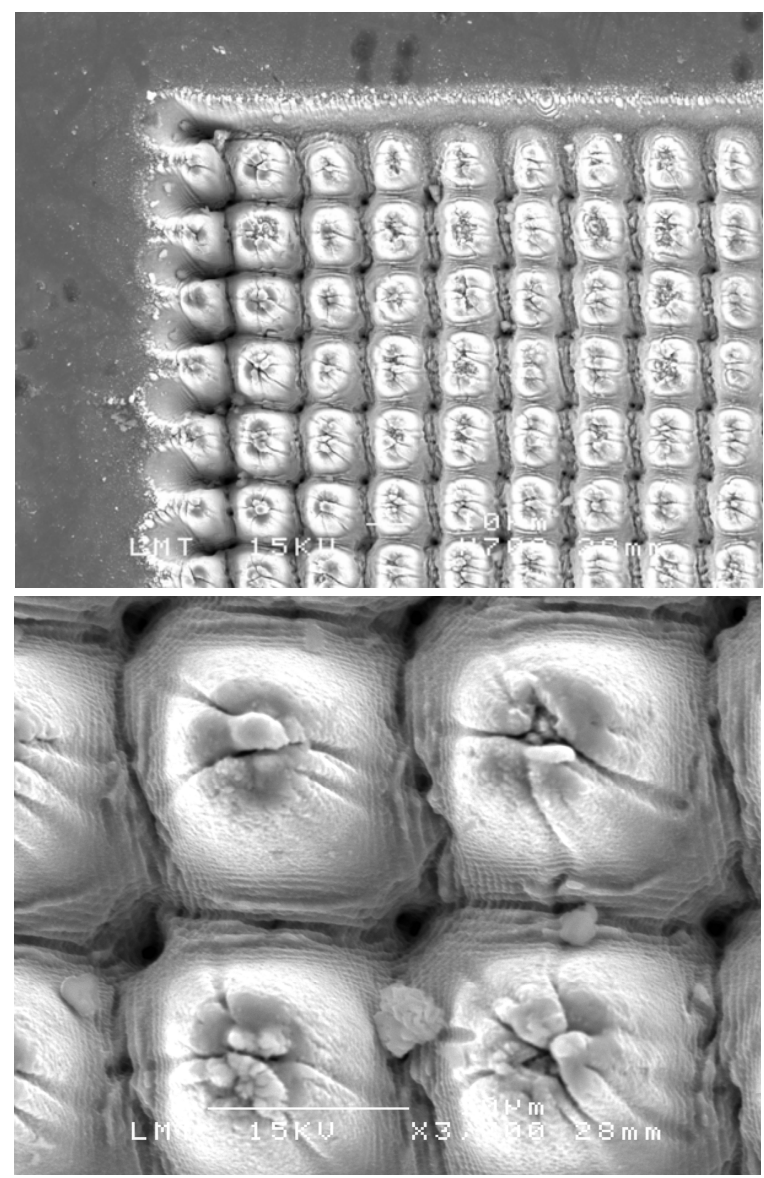

Figure 4 SEM images of (partly) textured Ti-6Al-4V sample. Processing parameters: fluence $0.12 \mathrm{~J} / \mathrm{cm}^{2}$, pulse frequency $200 \mathrm{kHz}$, beam velocity $200 \mathrm{~mm} / \mathrm{s}$, hatch distance $18 \mu \mathrm{m}, 40$ overscans, laser wavelength: $343 \mathrm{~nm}$ (upper figure) and $515 \mathrm{~nm}$ (lower figure).

Figure 6 shows an SEM image of a HMDSO coated sample, which was laser machined. It was found that at hatch distances of less than $60 \mu \mathrm{m}$, the coating was completely removed from the sample. That is because, the transmittance of a HMSDSO coating at the wavelength of the laser light $(343 \mathrm{~nm})$ is high [9]. As a result, a significant percentage of the laser light penetrates through the $8 \mu \mathrm{m}$ coating and ablates the steel substrate. The corresponding ejection of ablated material blows the coating from the substrate. It was found that, only when the hatch distance is larger than about $60 \mu \mathrm{m}$, parts of the coating remain.
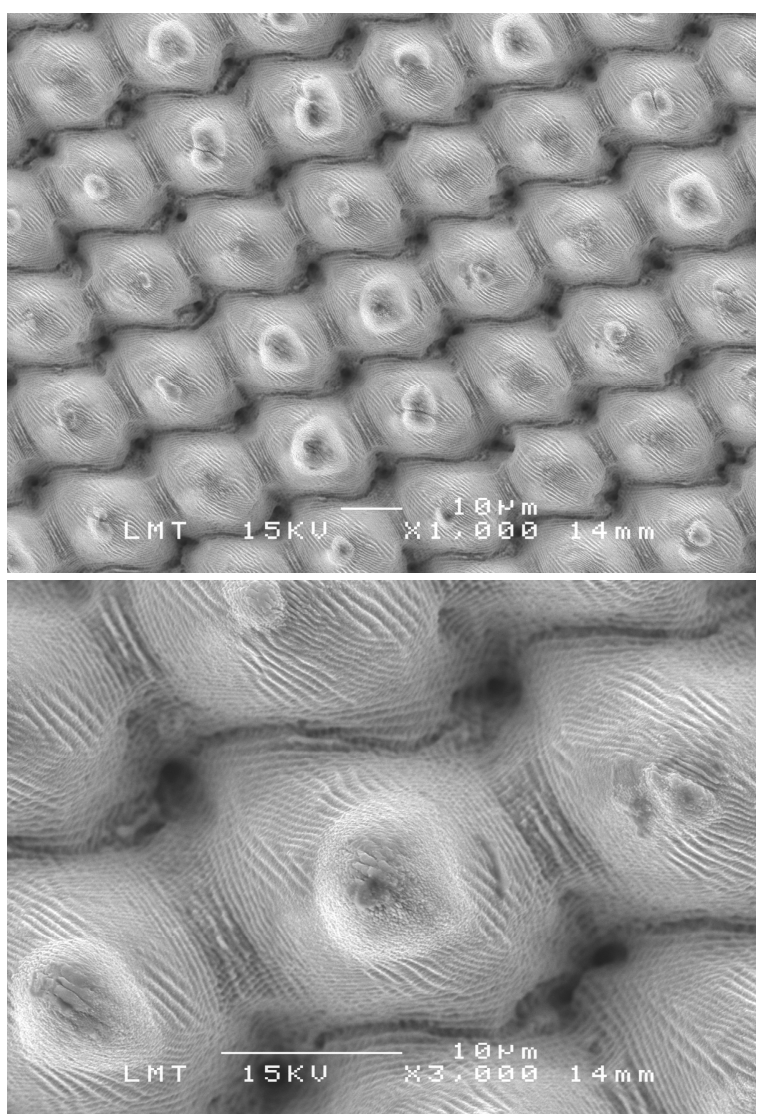

Figure 5 SEM images of textured stainless steel sample. Processing parameters: fluence $0.24 \mathrm{~J} / \mathrm{cm}^{2}$, pulse frequency $200 \mathrm{kHz}$, beam velocity $200 \mathrm{~mm} / \mathrm{s}$, hatch distance $18 \mu \mathrm{m}, 50$ overscans, laser wavelength $343 \mathrm{~nm}$.

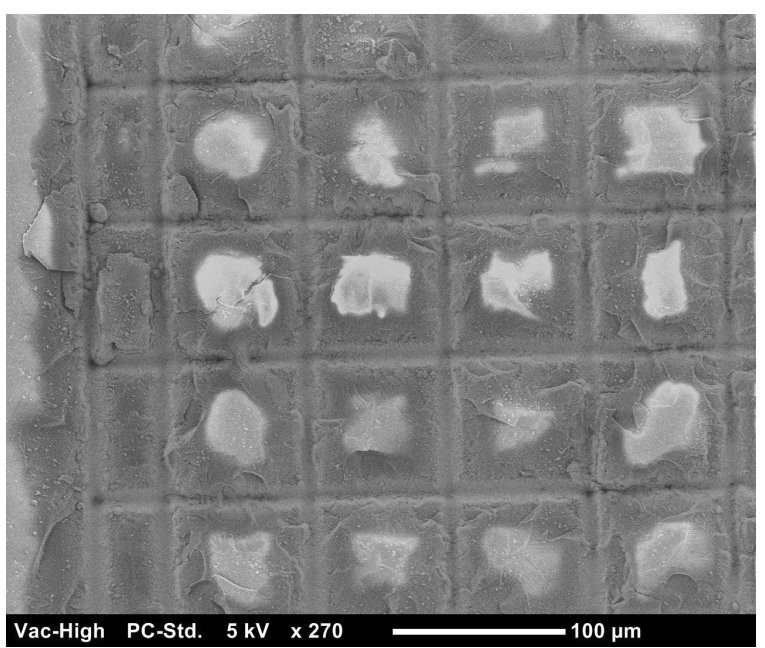

Figure 6 SEM image of (partly) textured HMDSO coated stainless steel sample. Processing parameters: fluence $0.12 \mathrm{~J} / \mathrm{cm}^{2}$, pulse frequency $200 \mathrm{kHz}$, beam velocity $50 \mathrm{~mm} / \mathrm{s}$, hatch distance $80 \mu \mathrm{m}, 10$ over scans, laser wavelength $343 \mathrm{~nm}$. 


\section{Contact angles}

Minutes after the laser treatment, the droplets were found to wet the structured area of the uncoated samples completely. That is, initially, the samples exhibit super-hydrophilicity, that is showing a contact angle of much less than $90^{\circ}$. But over time (ranging from hours to days), large contact angles, as high as $161^{\circ}$, were measured, see Figure 7.

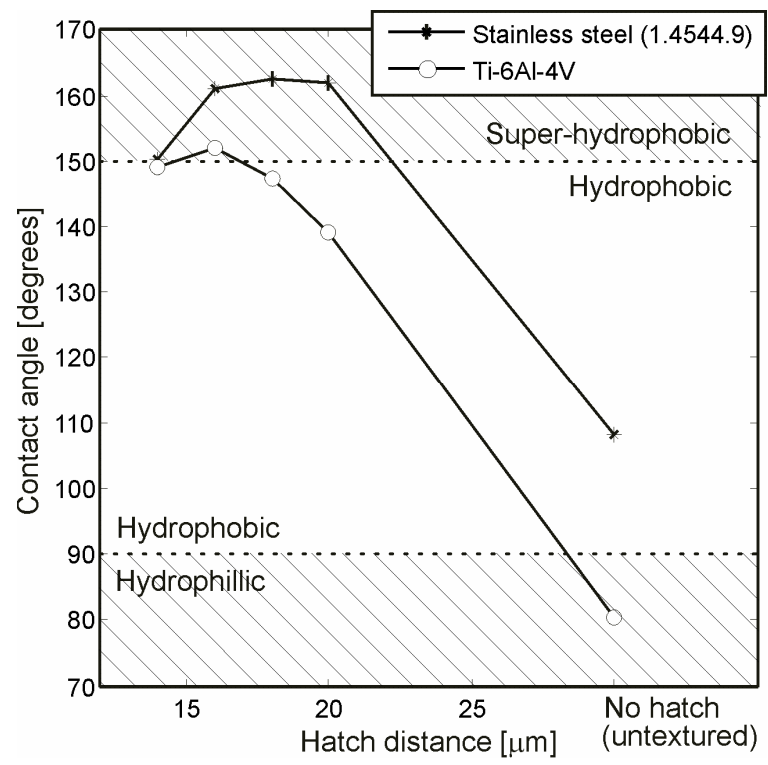

Figure 7 Contact angle as a function of hatch distance of uncoated samples, several days after laser micromachining.

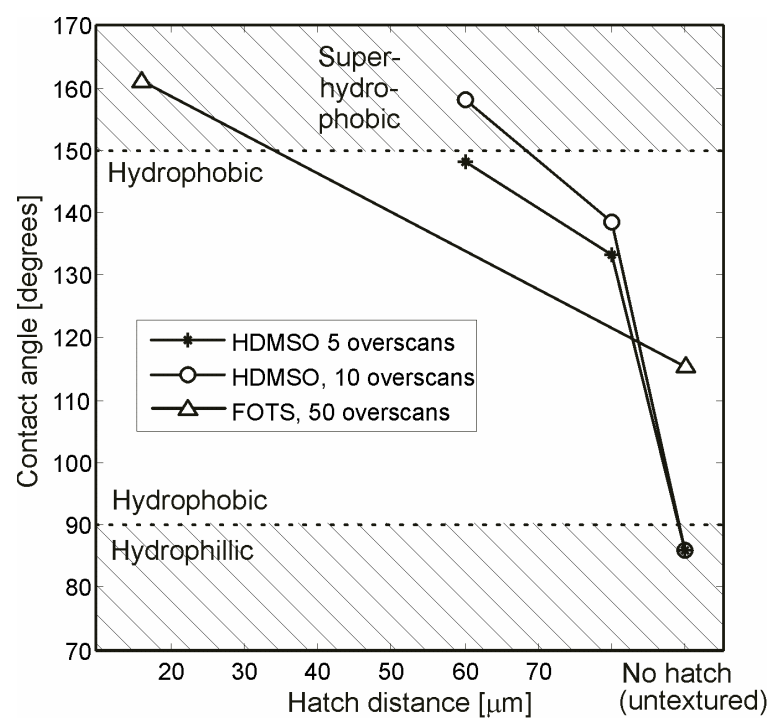

Figure 8 Contact angle as a function of hatch distance of HDMSO and FOTS coated samples.
Hence, the initially hydrophilic uncoated samples become super-hydrophobic over time. Kietzig, Hatzikiriakos and Englezos attribute this change in wettability to a certain extent to the presence of carbon on the laser irradiated surfaces [4]. That is, they showed a positive correlation between the changing (increasing) measured contact angles of laser textured surfaces and the changing (increasing) carbon content in the surface. They show that the rate of change in wetting behaviour with time depends on the roughness of the surface structure and the type of material, to vary from a few hours to almost a month. It needs to be verified that this phenomenon also explains the increasing hydrophobicity of the samples under consideration.

Figure 8 shows the measured contact angle of HDMSO and FOTS coated samples as a function of hatch distance. Also, this figure shows that, a dual scale micro-nano surface morphology increases the hydrophobicity of the samples significantly.

The contact angles of the uncoated and coated samples at low temperatures could unfortunately not be measured reproducibly, and are therefore omitted here.

Icing tests

Figure 9 shows a photograph of the sample after 20 minutes in rime conditions in the Eisomat. The thickness of the rime layer on the FOTS coated, but untextured, stainless steel was measured to be 400 $\mu \mathrm{m}$, whereas the thickness on the textured area was 350 to $400 \mu \mathrm{m}$. Hence, it can be concluded that the texture slightly slows down the formation of rime. Figure 10 shows a sample at the end of the ice rain test. As can be observed the laser textured area is almost completely free of ice, while the untextured area is uniformly covered with a significant number of frozen water drops. 


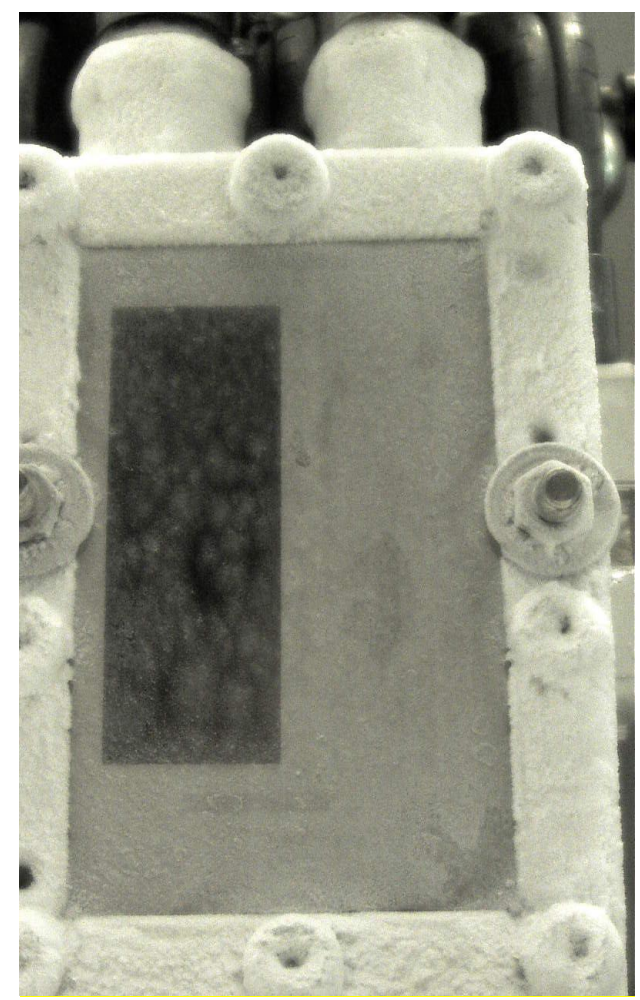

Figure 9 FOTS coated stainless steel after rime test. Black: laser textured area. Gray: untextured area.

\section{Conclusions}

By controlling the micro-nano surface texture, it is possible to modify the natural hydrophobicity of materials. The anti-ice properties of coated hydrophobic micro-nano surface textures were studied. Two materials, a titanium alloy (Ti-6Al-4V) and a stainless steel 1.4544.9, were laser-machined using ultra short laser pulses laser pulses of $6.7 \mathrm{ps}$ at $200 \mathrm{kHz}$. It was found that, minutes after the laser treatment, the samples exhibit super-hydrophilicity, but over time (ranging from hours to days), the samples exhibit super-hydrophobicity. Kietzig, Hatzikiriakos and Englezos attribute this change in wettability to a certain extent to the presence of carbon on the laser irradiated surfaces. It needs to be verified that this phenomenon also explains the increasing hydrophobicity of the samples under consideration. Thin Perfluorinated OctylTrichloroSilane (FOTS) and HexaMethylDiSilOxane (HMDSO) coatings were applied on top of the textures to create super-hydrophobicity. Rime tests show that the laser generated surface texture only slightly slows down the formation of rime on the coated surface, but that it dramatically improves the anti-ice properties of the surface.

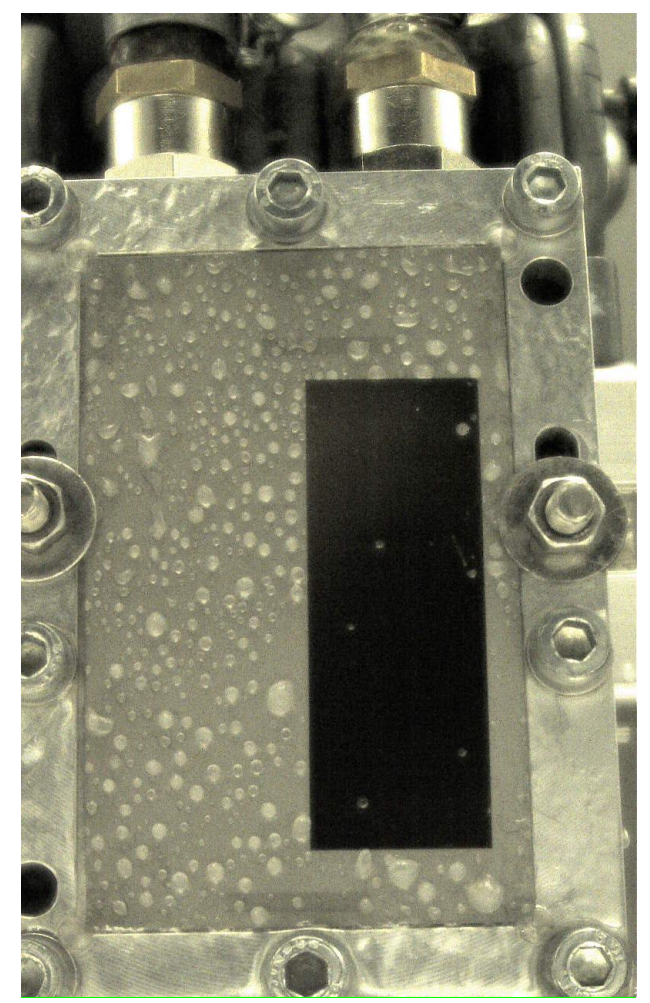

Figure 10 FOTS coated stainless steel after ice rain test. The laser textured area (black) is almost completely free of frozen droplets.

\section{References}

[1] FAA Federal Aviation Regulations, Part 25: Airworthiness standards: Transport category airplanes, Subpart B Flight, Safety Equipment, Ice protection.

[2] Liu, Z., Gou, Y., Wang, J \& Cheng, S. (2008) Frost formation on a super-hydrophobic surface under natural convection conditions, International Journal of Heat and Mass Transfer 51, 5975-5982.

[3] Koch, K. \& Barthlott, W. (2009) Superhydrophobic and superhydrophilic plant surfaces: an inspiration for biomimetic materials, Philosophical Transactions of the Royal Society A 367, 1487-1509.

[4] Kietzig, A.M., Hatzikiriakos, S.G. \& Englezos, P. (2009) Patterned superhydrophobic metallic surfaces, Langmuir, 25(8), pp 4821-4827.

[5] Meijer, J., Du, K., Gillner, A., Hoffmann, D., Kovalenko, V., Masuzawa, T., Ostendorf, A., Poprawe, R., Schulz, W. (2002) Laser machining by short and ultrashort pulses, State of the art and new 
opportunities in the Age of the Photons, Annals of the CIRP, 51/2:531,550.

[6] Reif, J. et al. (2006) Self-organized Surface Nanostructuring by Femtosecond Laser Processing, in: Perrière, J., Millon, E., Fogarassy, E. (Eds.), Recent Advances in Laser Processing of Materials, pp. 275-290.

[7] Römer, G.R.B.E., Huis in’t Veld, A.J., Meijer, J. \& Groenendijk, M.N.W. (2009) On the formation of laser induced self-organizing nanostructures, CIRP Annals - Manufacturing Technology, 58, 201-204.

[8] Geerken, M.J. (2006) Emulsification with microengineered devices. Dissertation, University of Twente, The Netherlands.

[9] Chen, H.L. \& Wang, L.A. (1999) Hexamethyldisiloxane film as the bottom antireflection coating layer for ArF excimer lithography, Applied optics, 38(22), pp. 4885-4890.

[10] Groenendijk, M.N.W. (2008) Fabrication of Super Hydrophobic Surfaces by fs Laser Pulses, Laser Technik Journal, 5(3), pp. 44-47.

\section{Acknowledgements}

The NL-cluster, and as such, the research leading to these results has received funding from the European Community's Seventh Framework Programme FP7/2007-2013 for the Clean Sky Joint Technology Initiative (JTI) under grant agreement $\mathrm{n}^{\circ}$ CSJUGAM-SFWA-2008-001.

The authors would like to thank Volkmar Stenzel, Dirk Salz, Björn Weber and Mathias Widrat from the Fraunhofer-Institut für Fertigungstechnik und Angewandte Materialforschung (IFAM) in Bremen, Germany for kindly providing the (coated) stainless steel samples and for the assistance with the icing experiments. In addition, we thank Nico Boer from ADSE Consulting and Engineering, Hoofddorp, the Netherlands for his contribution on icing conditions. Rob Lammertink and Halil Can Aran from the Membrane Technology group, of the University of Twente, the Netherlands are thanked for applying the FOTS coatings. Finally Laura Vargas from the Chair of Production Technology of the University of Twente is thanked for providing SEM images.

\section{Meet the Authors}

Gert-willem Römer received his PhD-degree Mechanical Engineering from the University of Twente in the Netherlands. Currently he is an Associate Professor of the Chair of Applied Laser Technology of the Faculty of Engineering Technology of the same university. His scientific focus is on the development of laser-processes, process-sensors, the modeling and real-time control of laser-material processing, applied to laser welding, cladding using high power lasers, as well as micro-machining using ultra short pulse lasers.

Daniel Arnaldo del Cerro received his Chemical Engineer Master degree from the University of Oviedo in Spain. After an internship at the Laser Zentrum Hannover (Germany), he joined the Chair of Applied Laser Technology of the Faculty of Engineering Technology of the University of Twente in The Netherlands as a $\mathrm{PhD}$ candidate on laser micromachining using ultra short pulse lasers.

Max Groenendijk received his Mechanical Engineering Master degree at the University of Twente, were he started his PhD project on Lotus surfaces produced by femtosecond laser texturing. He founded the spin-off company Lightmotif that is dedicated to ultra short pulse laser micromachining and surface texturing. The company offers applications and process development as well as job-shop services. Longterm development aims at self-cleaning surfaces enabled by laser textured surfaces.

Ronald Sipkema is co-founder of Lightmotif. With a background in physics as well as software engineering he is responsible for developing machining strategies and control software used by Lightmotif. His main interest is in the design of laser machining workstations and their low-level software interface.

Prof. Bert Huis in ' $t$ Veld is a full professor, leading the Chair of Applied Laser Technology of the University of Twente, and also works at TNO (the Netherlands Organisation for Applied Scientific Research) in Eindhoven, in the Netherlands. Key focus of his work is on laser-material interaction during micro-machining, cladding and welding. Special attention is paid to machining using ultra short laser pulses for different applications. Both removal and additive processes are studied, ranging from scribing and dicing to laser assisted deposition. 